\title{
Modeling the radiative effects of desert dust on weather and regional climate
}

\author{
C. Spyrou ${ }^{1}$, G. Kallos ${ }^{1}$, C. Mitsakou ${ }^{1,2}$, P. Athanasiadis ${ }^{1,3}$, C. Kalogeri ${ }^{1}$, and M. J. Iacono ${ }^{4}$ \\ ${ }^{1}$ University of Athens, School of Physics, Division of Environmental Physics-Meteorology, Bldg PHYS-V, 15784, \\ Athens, Greece \\ ${ }^{2}$ King's College London, Environmental Research Group, Franklin-Wilkins Building, 150 Stamford Street, \\ London SE1 9NH, UK \\ ${ }^{3}$ Centro Euro-Mediterraneo per i Cambiamenti Climatici, Viale Aldo Moro, 44 I, 40127 Bologna, Italy \\ ${ }^{4}$ Atmospheric and Environmental Research (AER), 131 Hartwell Avenue, Lexington, MA 02421-3126, USA
}

Correspondence to: G. Kallos (kallos@mg.uoa.gr)

Received: 21 November 2012 - Published in Atmos. Chem. Phys. Discuss.: 11 January 2013

Revised: 22 April 2013 - Accepted: 1 May 2013 - Published: 4 June 2013

\begin{abstract}
Mineral dust aerosols exert a significant effect on both solar and terrestrial radiation. By absorbing and scattering, the solar radiation aerosols reduce the amount of energy reaching the surface. In addition, aerosols enhance the greenhouse effect by absorbing and emitting outgoing longwave radiation. Desert dust forcing exhibits large regional and temporal variability due to its short lifetime and diverse optical properties, further complicating the quantification of the direct radiative effect (DRE). The complexity of the links and feedbacks of dust on radiative transfer indicate the need for an integrated approach in order to examine these impacts.

In order to examine these feedbacks, the SKIRON limited area model has been upgraded to include the RRTMG (Rapid Radiative Transfer Model - GCM) radiative transfer model that takes into consideration the aerosol radiative effects. It was run for a 6 year period. Two sets of simulations were performed, one without the effects of dust and the other including the radiative feedback. The results were first evaluated using aerosol optical depth data to examine the capabilities of the system in describing the desert dust cycle. Then the aerosol feedback on radiative transfer was quantified and the links between dust and radiation were studied.

The study has revealed a strong interaction between dust particles and solar and terrestrial radiation, with several implications on the energy budget of the atmosphere. A profound effect is the increased absorption (in the shortwave and longwave) in the lower troposphere and the induced modification of the atmospheric temperature profile. These feed-
\end{abstract}

backs depend strongly on the spatial distribution of dust and have more profound effects where the number of particles is greater, such as near their source.

\section{Introduction}

Mineral dust produced from arid and semi-arid areas of the world is injected into the atmosphere under favorable meteorological conditions. Aerosols exert a significant effect on both solar and terrestrial radiation (Tegen et al., 1996; Sokolik et al., 2001; Haywood et al., 2003; Yoshioka et al., 2007; IPCC, 2007; Kallos et al., 2009), also known as the direct aerosol effect or DRE (IPCC, 2007). By absorbing and scattering solar radiation, aerosols reduce the amount of energy reaching the surface (Kaufman et al., 2002; Tegen, 2003; Kallos et al., 2009; Spyrou et al., 2010). Moreover, aerosols enhance the greenhouse effect by absorbing and emitting outgoing longwave radiation (Dufrense et al., 2001; Tegen, 2003; Heinold et al., 2008; Pandithurai et al., 2008).

As a second type of effect, aerosols function as particles on which water vapor accumulates during cloud droplet formation, acting as cloud condensation nuclei (Levin et al., 2005; Solomos et al., 2011). Modifications of the number concentration or the hygroscopic properties of dust tend to modify the physical and radiative properties of clouds (Twomey, 1977; Khan et al., 2009) and the possibility and intensity with which a cloud can precipitate (e.g. Liou and $\mathrm{Ou}$, 
1989; Albrecht, 1989; Solomos et al., 2011). All the various changes in cloud processes imposed by aerosols are referred to as aerosol indirect effects (e.g. Solomos et al., 2011). Finally, by absorbing solar radiation, particles contribute to the reduction in cloudiness, a phenomenon referred to as the semi-direct effect (Khan et al., 2009).

The magnitude of the feedback on the radiative transfer depends strongly on the optical properties of particles (single scattering albedo, asymmetry parameter, extinction efficiency), which in turn depend on the size, shape and refractive indices of dust particles (Tegen, 2003; Pace et al., 2006; Helmert et al., 2007). The mineral composition of the dust source areas, as well as the chemical composition and transformation of aerosols during their transportation, are all factors that influence the magnitude of the dust feedback (Tegen, 2003; Wang et al., 2005; Astitha et al., 2010). Furthermore, the vertical distribution of dust, the presence of clouds and the albedo of the surface all contribute to the DRE (Sokolik and Toon, 1996; Tegen and Lacis 1996; Liao et al., 2004; Helmert et al., 2007).

Several studies have focused on calculating the radiative feedback of dust on a global scale: Liao et al. (2004) found a decrease in the incoming shortwave radiation of $0.21 \mathrm{Wm}^{-2}$, while the longwave radiation increased by $0.31 \mathrm{Wm}^{-2}$. Reddy et al. (2005) simulated a decrease of $0.28 \mathrm{Wm}^{-2}$ on the shortwave and an increase of $0.14 \mathrm{Wm}^{-2}$ on the longwave. Other studies and measurements have produced similar values for the global dust radiative effect (IPCC, 2007). However, little work has been done to incorporate the dust radiative feedback in regional and mesoscale models (Stokowski, 2005).

If we look at the radiative impacts at a local scale during dust episodes, the DRE exhibits much stronger signals. Haywood et al. (2003) measured a decrease of incoming shortwave radiation up to $130 \mathrm{Wm}^{-2}$ (instantaneous value) on the coast of West Africa during the passage of a dust storm in September 2000. During a severe dust episode in Niger on 3-12 March 2006, the ARM (Atmospheric Radiation Measurement) mobile facility detected a maximum shortwave decrease of $250 \mathrm{Wm}^{-2}$ on the surface, where at the same time the reflected radiation at the top of the atmosphere increased by $100 \mathrm{Wm}^{-2}$ (Slingo et al., 2006). For the same episode, the emitted longwave radiation at the surface decreased by approximately $100 \mathrm{Wm}^{-2}$, corresponding to the "cooling" imposed by dust shading. Another intense dust event producing similar radiative perturbations, both in the shortwave and longwave spactral ranges, was reported in the Mediterranean basin in March 2010 (di Sarra et al., 2011).

The local effects of airborne dust have been thoroughly examined in a number of other studies. The main purpose of this work is to examine the long-term implications of the dust-radiation interactions. In order to model these diverse feedbacks on the radiation balance, the SKIRON/Dust limited area model has been used (Kallos et al., 1997a, b; Papadopoulos et al., 2002; Kallos et al., 2006; Spyrou et al.,
2010). Continuing from these studies, the model has been updated further to include the Rapid Radiative Transfer Model - RRTMG (Mlawer et al., 1997; Oreopoulos et al., 1999; Iacono et al., 2003; Pincus et al., 2003; Barker et al., 2003; Clough et al., 2005; Morcette et al., 2008; Iacono et al., 2008). The addition of the RRTMG scheme has made it possible to model and study the effects of desert dust particles on the radiation balance of the atmosphere.

The following section summarizes the main characteristics of the modeling system, while Sect. 4 outlines the new radiative transfer scheme that was incorporated in the SKIRON/Dust system. Section 5 depicts the optical properties of suspended particles and in particular dust aerosols that are discussed in the present study. The experimental setup that was designed for the present simulations is described in Sect. 6. The model evaluation and the sensitivity tests for the estimation of the energy impact are analyzed in Sects. 7 and 8 , respectively. Finally, the last section summarizes the main conclusions of the study.

\section{SKIRON/Dust modeling system}

The SKIRON/Dust modeling system is based on the atmospheric model SKIRON, which has been developed at the University of Athens from the Atmospheric Modeling and Weather Forecasting Group (Kallos et al., 1997; Nickovic et al., 2001; Kallos et al., 2006; Spyrou et al., 2010) within the framework of a number of projects (SKIRON, MEDUSE, ADIOS, CIRCE and recently MARINA Platform). A dust module that simulates the production and removal of the desert dust aerosol is directly coupled with the host model. The dynamical core of the model is based on the ETA concept, which was originally developed by Mesinger $(1984,1988)$ and Janjic $(1990,1994)$. The SKIRON atmospheric model includes several sophisticated parameterization schemes, such as the OSU (Oregon State University) scheme (Ek and Mahrt, 1991) for simulation of the surface processes, including a data assimilation scheme for soil temperature and soil wetness, and the option of choosing among Betts-Miller-Janjic (Betts, 1986) and Kain-Fritsch (Kain and Fritsch, 1990) convective parameterization schemes for the representation of moisture processes. During the SKIRON/Dust runs, the prognostic atmospheric and hydrological conditions are used in order to calculate the effective rates of the injected dust concentration based on viscous/turbulent mixing, soil composition, soil moisture, shear-free convection and diffusion (Papadopoulos et al., 2002). The dust module includes a particle size distribution in order to simulate more accurately the size-dependent processes. In the current form of the modeling system, the transport mode uses eight size bins (log-normally distributed) with effective radius $0.15,0.25,0.45,0.78,1.3,2.2,3.8,7.1 \mu \mathrm{m}$ (Table 1 ).

Recently, the modeling system was significantly upgraded in order to improve the model prediction efficiency, meeting 
Table 1. The 8 transport size bins used by the SKIRON/Dust model. $r_{\min }$ and $r_{\max }$ are the minimum and maximum radius of each bin, $r_{n}$ the mass median diameter, $r_{\text {eff }}$ the effective radius and $\sigma_{g}$ the standard deviation of the lognormal distribution.

\begin{tabular}{cccccc}
\hline Bin & $\mathrm{r}_{\min }$ & $\mathrm{r}_{\max }$ & $\mathrm{r}_{\text {eff }}$ & $\mathrm{r}_{n}$ & $\sigma_{g}$ \\
\hline 1 & 0.1 & 0.18 & 0.15 & & \\
2 & 0.18 & 0.3 & 0.25 & & \\
3 & 0.3 & 0.6 & 0.45 & & \\
4 & 0.6 & 1 & 0.78 & & \\
5 & 1 & 1.8 & 1.3 & 0.2986 & 2 \\
6 & 1.8 & 3 & 2.2 & & \\
7 & 3 & 6 & 3.8 & & \\
8 & 6 & 10 & 7.1 & & \\
\hline
\end{tabular}

the current needs for accurate simulation of the mineral dust cycle and the interaction mechanisms with various atmospheric processes. New features include improvements in the description of the bottom boundary (ground or sea surface) characteristics of the atmospheric model and the dust aerosol properties (Spyrou et al., 2010). The new model version includes a 16-category soil characteristics dataset (Miller and White, 1998) that provides detailed information on soil physical properties, such as porosity and available water capacity. A high-resolution (30 s) global land use/land cover database including urban areas and classified according to the 24category USGS land use/land cover system (Anderson et al., 1976 ) is utilized. For a more accurate description of the topographic variability that determines the incoming solar radiation reaching the surface, in the upgraded SKIRON/Dust model a new preprocessor was developed that derives statistics for the slope steepness and orientation from the high resolution topography datasets. The dust aerosol is described by using the three-modal lognormal function of D'Almeida (1987) for the aerosol mass distribution at the source areas and the 8 size bin transport mode of Schulz et al. (1998) for the long-range transported particles. The dust particles are assumed to be mobilized through the process of saltation bombardment (Marticorena and Bergametti 1995) and deposited via dry (diffusion, impaction, gravitational settling) and wet (in-cloud and below-cloud removal) mechanisms. More details on the specific characteristics of the atmospheric model are provided in Spyrou et al. (2010).

\section{Rapid Radiative Transfer Model - RRMTG}

Longwave and shortwave radiative transfer in the SKIRON/Dust model are parameterized with RRTMG (Mlawer et al., 1997; Iacono et al., 2003; Iacono et al., 2008), a broadband correlated k-distribution radiation model developed at AER, Inc. with support from the US Department of Energy. Both RRTMG and the related single-column, reference radiation model, RRTM, were developed in the context of continual comparison to Line-by-line Radiative Transfer Model - LBLRTM, which is an accurate and highly flexible model that continues to be validated with measured atmospheric radiance spectra from the sub-millimeter to the ultraviolet (Clough et al., 2005; Turner et al., 2004). This approach realizes the goal of providing an improved radiative transfer capability that is directly traceable to measurements. Molecular absorbers in RRTMG include water vapor, ozone, carbon dioxide, nitrous oxide, methane, oxygen, nitrogen and four halocarbons (CFC11, CFC12, CFC22, and CCL4) in the longwave and water vapor, carbon dioxide, ozone, methane and oxygen in the shortwave. The water vapor continuum is based on CKD_v2.4, and molecular line parameters are based on HITRAN 2000 for water vapor and HITRAN 1996 for all other molecules (Iacono et al., 2008; Rothman et al., 2009). RRTMG uses sixteen spectral bands to represent the longwave region, while the shortwave band is represented by fourteen spectral intervals. The UV/visible and near-IR surface albedo are defined using the $30 \mathrm{~s}$ global land use database of the US Geological Survey (Anderson et al., 1976). Absorption and emission from aerosols and clouds are included in the longwave, and the shortwave treatment includes extinction (absorption plus scattering) from aerosols, clouds and Rayleigh scattering. Aerosol radiative effects are treated in RRTMG through the specification of their optical properties within each spectral interval. For the dust particles the Henyey-Greenstein (1941) phase function is applied.

RRTMG incorporates several modifications to RRTM (while retaining the same basic physics and absorption coefficients) in order to improve computational efficiency, to update the code formatting for easier application to global and limited area models, and to represent sub-grid scale cloud variations. The complexity of representing fractional cloudiness and cloud overlap in the presence of multiple scattering is addressed in RRTMG with the use of McICA, the Monte-Carlo Independent Column Approximation (Pincus et al., 2003), which is a statistical technique for representing radiative impacts of sub-grid scale on cloud variability, including cloud overlap. The maximum-random cloud overlap assumption is applied within RRTMG in the SKIRON/Dust model.

\section{Optical properties of dust}

The absorption and scattering of light by a homogeneous spherical particle is a classic problem in physics, the mathematical formulation of which is referred to as Mie theory (Bohren and Huffman, 1983). The most important factors that govern these processes are the wavelength of the incident radiation, the size of the particle, the ratio of the circumference of the particle to the wavelength and the complex refractive index, expressed as $\mathrm{RI}=n+i k$. The real part $n$ expresses attenuation due to scattering (non-absorbing), while 
Optical Properties of Dust

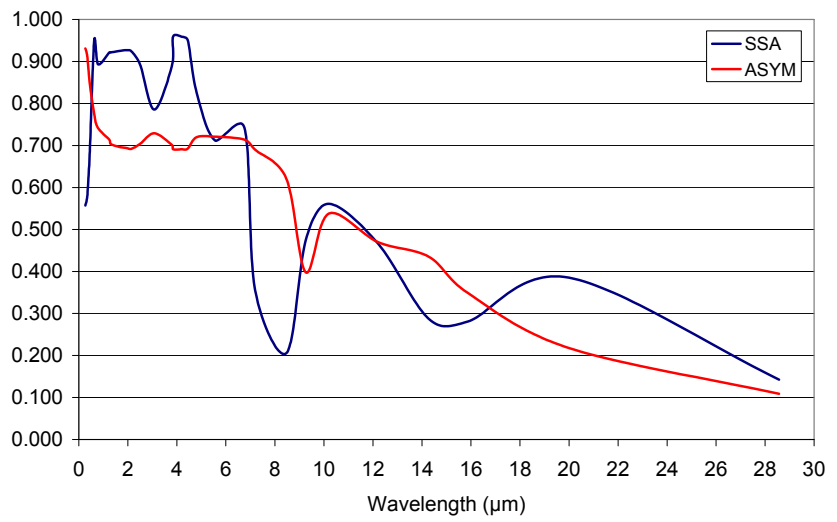

Fig. 1. Single scattering albedo (SSA - blue line) and asymmetry parameter (ASYM - red line) of dust particles used in this study.

the imaginary part is related to the absorption of light by the medium (Helmert et al., 2007).

The refractive indices of various spectral ranges, for all the particle sizes, have been determined using the OPAC (Optical Properties of Aerosols and Clouds) software package (Hess et al., 1998), which in turn utilizes the Mie theory for its calculations (Quenzel and Muller, 1978). The same package was used for the definition of the aerosol single scattering albedo $\omega$ and the asymmetry parameter $g$ for the same wavelengths. For the $550 \mathrm{~nm}$ spectral window, a single scattering albedo value of 0.95 was used (instead of the smaller value (0.83) provided by OPAC) for transported mineral dust. Field measurements suggest this value to be more realistic for desert dust in the mid-visible (Kalashnikova et al., 2005; Ralph Kahn personal communication, 2009). It should be noted here that the experimental quantification of the optical properties of dust is a complex matter and may lead to discrepancies between the various techniques used (Müller et al., 2012). Also, the combination of the optical properties of dust and the changes in the composition of particles further complicates the matter of dust forcing. In this study the values of single scattering albedo and asymmetry parameter are presented in Fig. 1.

For the calculation of the extinction efficiencies $Q_{\text {ext }, i}$ for each size bin $i$, at each wavelength $\lambda$, the Wiscombe Mie algorithm was used (Wiscombe, 1980; Mishchenko et al., 2002). Although dust particles are known to be non-spherical (Nakajima et al., 1989; Meloni et al., 2004), Mie calculations can be used to compute the radiative parameters for equivalent volume spheres and provide very good representation for non-spherical scattering (Tegen and Lacis, 1996).

The aerosol optical thickness at each wavelength $\tau(\lambda)$ was calculated by the following formula:

$\tau(\lambda)=\sum_{i=1}^{\mathrm{N}} \frac{3}{4 \rho r_{i}} \mathrm{DL}_{i} Q_{\mathrm{ext}, i}(\lambda)$ where $N=8$ is the number of particle size bins, $\rho=$ $2.65 \mathrm{~kg} \mathrm{~m}^{-3}$ is the particle density, $r$ is the particle radius (in $\mathrm{m}$ ), DL is the layer dust load (in $\mathrm{kg} \mathrm{m}^{-2}$ ) and $Q_{\text {ext }, i}(\lambda)$ is the extinction efficiency calculated from the Mie theory (Tegen and Lacis, 1996; Perez et al., 2006).

\section{Experimental design}

In order to evaluate and quantify the effects of desert dust particles on the radiation budget in the atmosphere, a series of test runs were carried out. The model was integrated for a period of six years (2002-2007) over an extended area that covers the European continent, the Mediterranean Sea and northern Africa, as well as a major part of the Middle East and Turkey. The horizontal grid increment was 0.25 . A vertical dimension of 38 levels was used, stretching from the surface up to $20 \mathrm{~km}$. The ECMWF operational analysis dataset (horizontal resolution of 0.25 degree) was used for the initial and lateral boundary conditions for the meteorological parameters. The time step was set at $60 \mathrm{~s}$ and the radiation driver was invoked every $15 \mathrm{~min}$.

The model runs were carried out under two different setups: (a) by neglecting the effects of dust particles on the radiative parameters (NDE) and (b) by including the dust-radiation interaction mechanisms (WDE). Between the two setups, the differences in the radiative fluxes and heating/cooling rates (for the entire spectral range), as well as other atmospheric parameters, are calculated and discussed in the following paragraphs.

\section{Model evaluation - Qualitative study and statistical techniques}

To estimate the impact on model performance of dustradiation interaction processes, a specific case of desert dust transport towards SE Europe was examined. On 5 April 2006, strong winds originating from across the southeastern side of the Atlas mountain range injected large quantities of mineral dust particles into the atmosphere. The particles were transported over the Mediterranean Sea and two days later, on 7 April 2006, reached Crete in the Eastern Mediterranean (Fig. 2). To evaluate the effects of dust on the radiative transfer, solar radiation data retrieved from a pyranometer located at the Technological University (TEI) of Crete were used (available through the AERONET site). Model runs with the two different setups (NDE, WDE) were carried out for the simulation of this test case.

During the passage of the dust plume, the incoming solar radiation decreased by approximately $200 \mathrm{Wm}^{-2}$ (Fig. 3). This abrupt change is depicted by the WDE simulation to a certain extent, but cannot be attributed solely on the shading effect of desert dust particles. One viable explanation is that the change in the radiation balance of the atmosphere, due to the presence of dust particles, led to cloud formation in the 


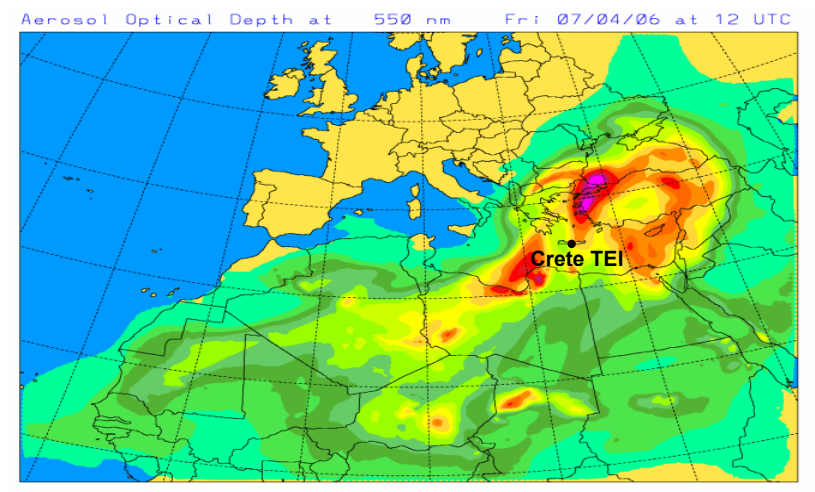

$\begin{array}{llllllllllllllllll}0.01 & 0.12 & 0.23 & 0.34 & 0.44 & 0.55 & 0.66 & 0.77 & 0.88 & 0.99 & 1.10 & 1.21 & 1.31 & 1.42 & 1.53\end{array}$

Fig. 2. AOD at $550 \mathrm{~nm}$ from the SKIRON/Dust model on 7 April 2006. The location of the measuring station in Crete is marked in the figure.

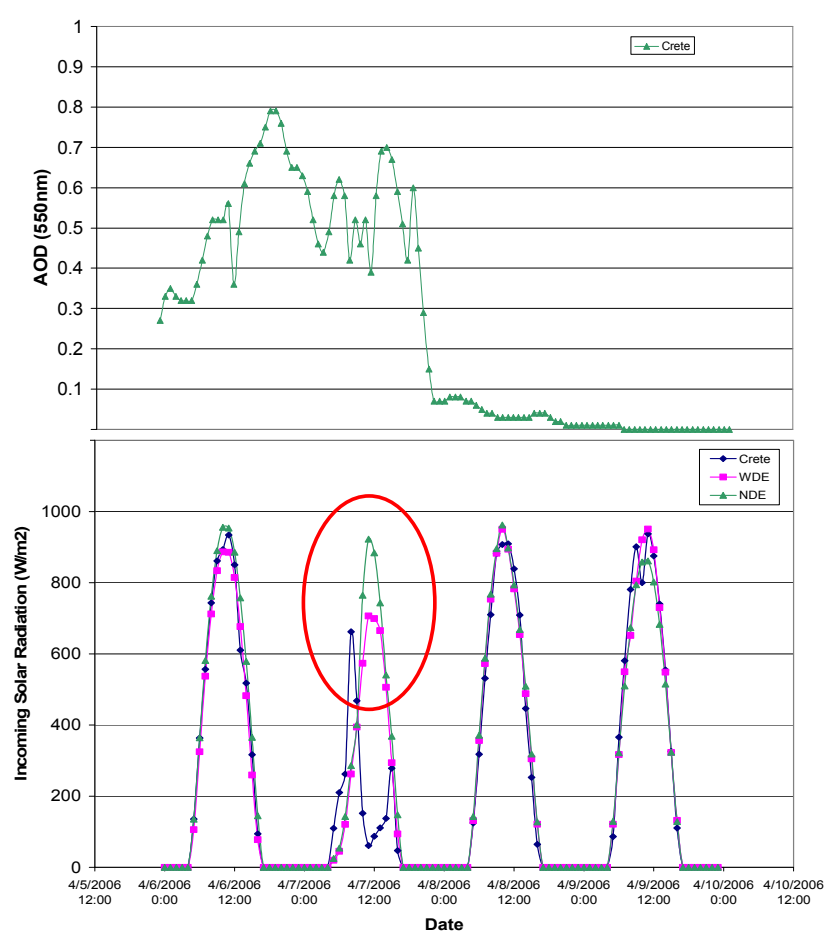

Fig. 3. Aerosol optical depth (AOD) at $550 \mathrm{~nm}$ at the station in Crete (top) derived from SKIRON model. Comparison of the incoming solar radiation at the surface in $\mathrm{Wm}^{-2}$ (bottom) as measured from the station in Crete (blue line) and as simulated by the SKIRON/Dust system with the two model setups (WDE - purple line; NDE - green line). The cloudy period is marked with the red oval.

area that is blocking the incoming solar radiation observed at the station in Crete.

To further investigate this hypothesis, the vertical profiles of the cooling rates have been derived. In Fig. 4, the cooling rates together with the vertical extent of dust concentration are shown. The cooling rates of the WDE simulation exhibit
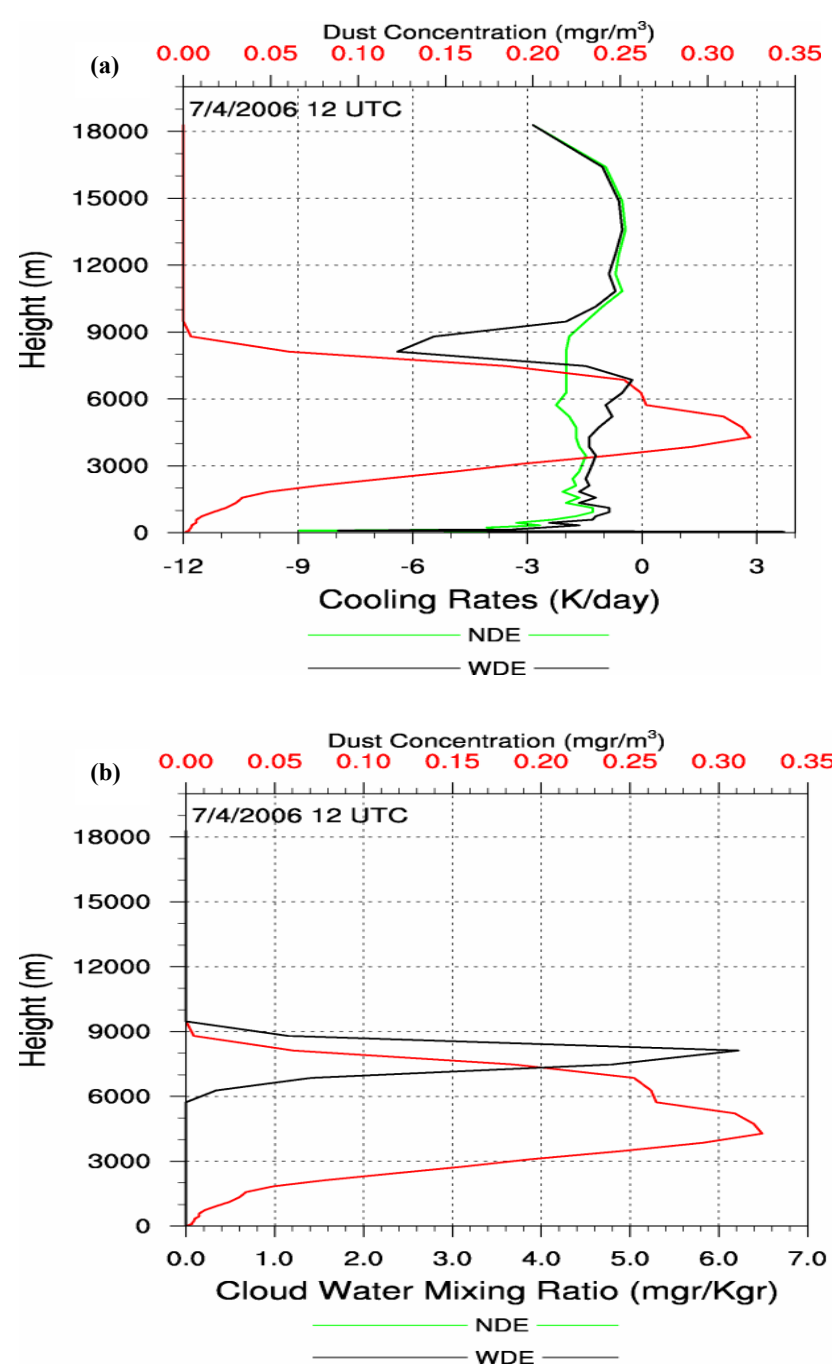

Fig. 4. Vertical distribution of (a) cooling rates and (b) cloud water mixing ratio ( $\mathrm{mgr} / \mathrm{Kgr}$ ) over the solar radiation station in Crete on 7 April 2006 at 12:00 UTC for both model setups (black line denotes WDE). For the NDE simulation, cloud water mixing ratio is zero. The vertical distribution of dust concentration in $\mathrm{mgr} \mathrm{m}^{-3}$ is also shown (red line).

a sharp decrease of $4 \mathrm{Kd}^{-1}$ just above the dust plume in a layer about $9 \mathrm{~km}$ high. The dust particles seem to have an albedo effect, partly reflecting back the incoming solar radiation. As a side effect of this reflection, cooling of the adjacent atmospheric layer over the dust plume is simulated. This temperature decrease drives the air temperature closer to the dew point temperature and leads to the formation of a cirrus cloud over the station in Crete, as shown in Fig. 5. The SKIRON/Dust model (WDE run) appears to capture this feature and the formation of a high altitude cloud over the station in Crete (Fig. 5, right), which in turn leads to the decrease of the simulated incoming solar radiation. 


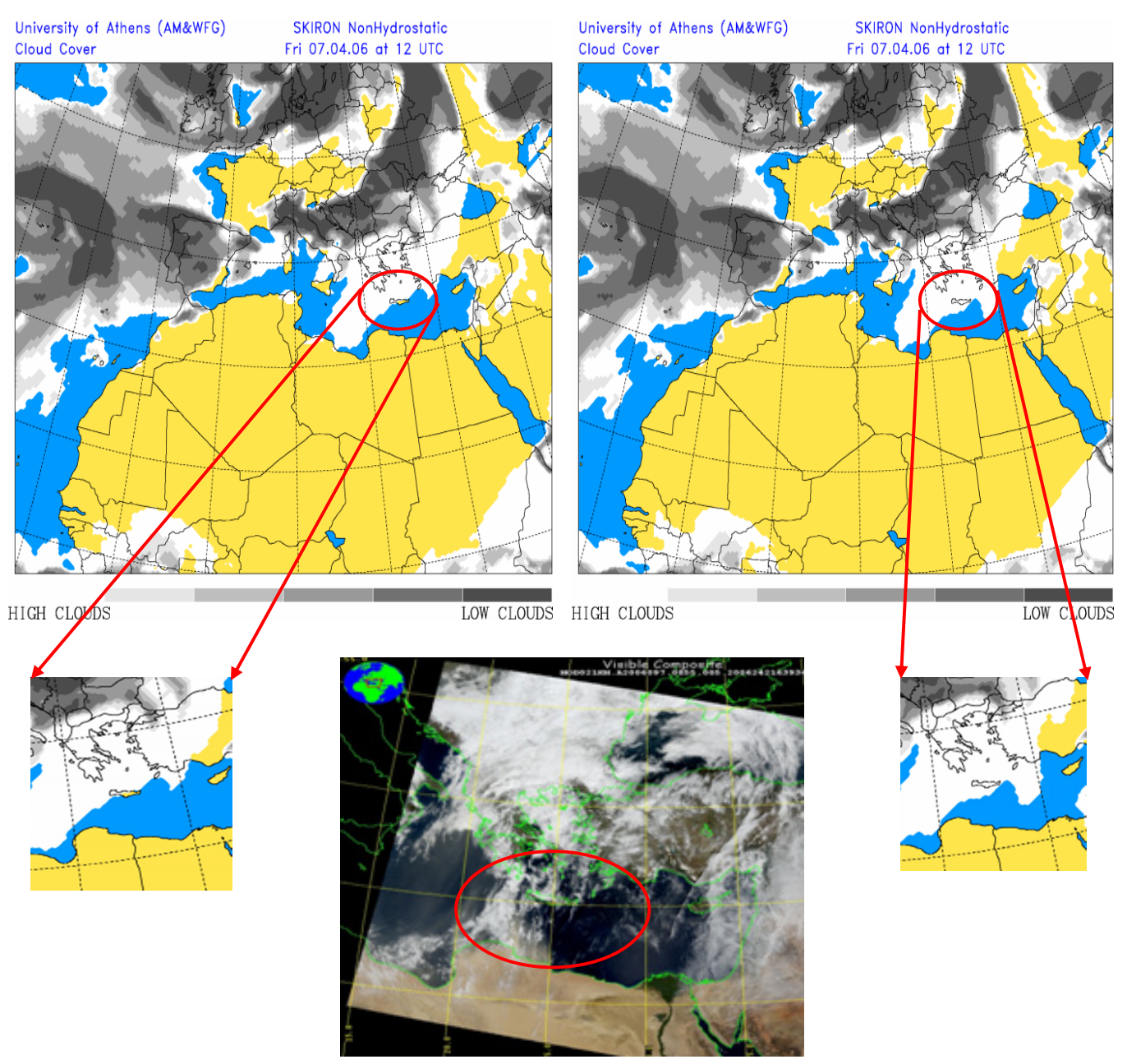

Fig. 5. Cloud cover distribution over the simulation domain on 7 April 2006 at 12:00 UTC for both model setups: in the left panel the NDE simulation and in the right panel the WDE simulation. In the bottom panel the actual cloud formations from the MODIS satellite are shown.

For a more thorough evaluation of the model performance, a series of statistics was derived. At first, in order to evaluate the radiation calculations, the model outputs were compared with measurements obtained from three of the AERONET network stations (Crete, Sede Boker and Moldova) for the year 2006. The characteristics of the stations (geographical location and altitude), as well as the statistical parameters (regression trend lines, correlation coefficients) determined from the analysis, are shown in Table 2. The flux comparisons were performed for the days of increased values of aerosol optical depth (AOD). Thus, AOD measurements at $500 \mathrm{~nm}$ from the AERONET stations were also obtained and the 95th and 99.5th percentiles were calculated for each dataset in order to detect the periods of increased aerosol optical depth in the atmosphere. The 95th percentile of AOD was found at about 0.3 , while the 99.5 th percentile fluctuated between 0.5 and 0.6 for the three studied sites. In general, the SKIRON/Dust model produces accurate simulations of the incoming radiation, since the correlation coefficients calculated for the compared datasets have high values and the linear regression slopes of the trend lines are close to unity.

However, the intercept of the regression lines, which indicate the difference between the simulated and the observed values, are very high and exceed 50 when the dust effects on radiation are not considered. This overestimation of the observed radiation fluxes by the model in the NDE setup is directly related to the neglection of the radiative effects of the dust aerosols. On the other hand, the inclusion of dustradiation interaction processes appears to diminish significantly this overestimation at Crete and Sede Boker, with a complete elimination noticed at Sede Boker $(-0.8)$ for AOD values greater than 0.6. The decrease of the model overestimation in Moldova (the most northern site out of the three) with the incorporation of dust effects appears to be negligible. Since the dust load that reaches Moldova is reduced compared to the amounts that affect the more south sites, the 
Table 2. Trend lines and correlation coefficients between modeled and measured incoming solar flux at Crete, Sede Boker and Moldova, taking into account days with increased AOD.

\begin{tabular}{|c|c|c|c|c|c|c|c|c|c|}
\hline \multirow{2}{*}{ Station } & \multirow{2}{*}{ Latitude, Longitude } & \multirow{2}{*}{ Altitude (m) } & \multicolumn{2}{|c|}{ AOD values } & & \multicolumn{2}{|c|}{ Trend lines } & \multicolumn{2}{|c|}{ Correlation coefficient } \\
\hline & & & $\mathrm{AOD}>95 \%$ & $\mathrm{AOD}>99.5 \%$ & & $\mathrm{AOD}>95 \%$ & $\mathrm{AOD}>99.5 \%$ & $\mathrm{AOD}>95 \%$ & $\mathrm{AOD}>99.5 \%$ \\
\hline \multirow{2}{*}{ Crete } & \multirow{2}{*}{ N $3520^{\prime}$, E $2517^{\prime}$} & \multirow{2}{*}{20} & \multirow{2}{*}{0.28} & \multirow{2}{*}{0.52} & No dust effect & $y=0.95 x+96$ & $y=0.86 x+153$ & $R^{2}=0.87$ & $R^{2}=0.74$ \\
\hline & & & & & Dust effect & $y=0.96 x+63$ & $y=0.88 x+87$ & $R^{2}=0.88$ & $R^{2}=0.72$ \\
\hline Sede Boker & N $3051^{\prime}$, E $3447^{\prime}$ & 480 & 0.30 & \multirow[t]{2}{*}{0.63} & No dust effect & $y=1.03 x+50$ & $y=1.06 x+62$ & $R^{2}=0.97$ & $R^{2}=0.97$ \\
\hline \multirow{2}{*}{ Moldova } & \multirow{2}{*}{ N $4700^{\prime}$, E $2849^{\prime}$} & \multirow{2}{*}{205} & \multirow{2}{*}{0.26} & & $\begin{array}{c}\text { Dust effect } \\
\text { No dust effect }\end{array}$ & $\begin{array}{l}y=0.99 x+20 \\
y=0.94 x+91\end{array}$ & $\begin{array}{l}y=1.04 x-0.8 \\
y=0.89 x+143\end{array}$ & $\begin{array}{l}R^{2}=0.96 \\
R^{2}=0.75\end{array}$ & $\begin{array}{l}R^{2}=0.98 \\
R^{2}=0.68\end{array}$ \\
\hline & & & & 0.48 & Dust effect & $y=0.93 x+90$ & $y=0.91 x+142$ & $R^{2}=0.76$ & $R^{2}=0.73$ \\
\hline
\end{tabular}

radiative forcing due to the suspension of dust particles is expected to be reduced.

To evaluate the impact of dust particles on the model calculation of air temperature, simulation runs for a 6-year period (2002-2007) were carried out with the same implementation of the SKIRON modeling system. The observations of air temperature close to the surface were collected from about 600 monitoring stations of the World Meteorological Organization network (WMO). For the two model setups (NDE, WDE), the bias, the root mean square error (RMSE) and the correlation coefficient $r$ were computed for each season of the year for the entire 6-year simulation period (Fig. 6), as described in Wilks (1995). It appears that the correlation coefficient is higher with the new modifications incorporated in the model and exceeds 0.90 throughout the year. The bias is reduced when the impacts of desert dust on radiation are considered (WDE case). This reduction is larger during Northern Hemisphere spring (MAM) and summer (JJA), two seasons with the highest number of Saharan dust intrusions towards Europe, and is smaller during winter (DJF) and autumn (SON). The improvement in the statistical scores for winter and autumn is attributed mostly to the stations near the source areas, where dust clouds are always present and constantly modify radiative transfer. The RMSE values show respective decreases with the incorporation of the dust-radiation interaction mechanisms ranging from $\sim 28 \%$ in autumn (SON) to $\sim 36 \%$ during the spring transitional period (MAM). In order to illustrate that the dust feedback is more profound near the sources, we calculate the above statistical scores for the spring (MAM) period for two sub-areas: North Africa (Fig. 7a) and Europe (Fig. 7b). The most profound variations are modeled over northern Africa near the dust sources.

In general, the inclusion of dust-radiation interaction processes appears to enhance the model performance in estimating the radiative fluxes and near surface air temperature.
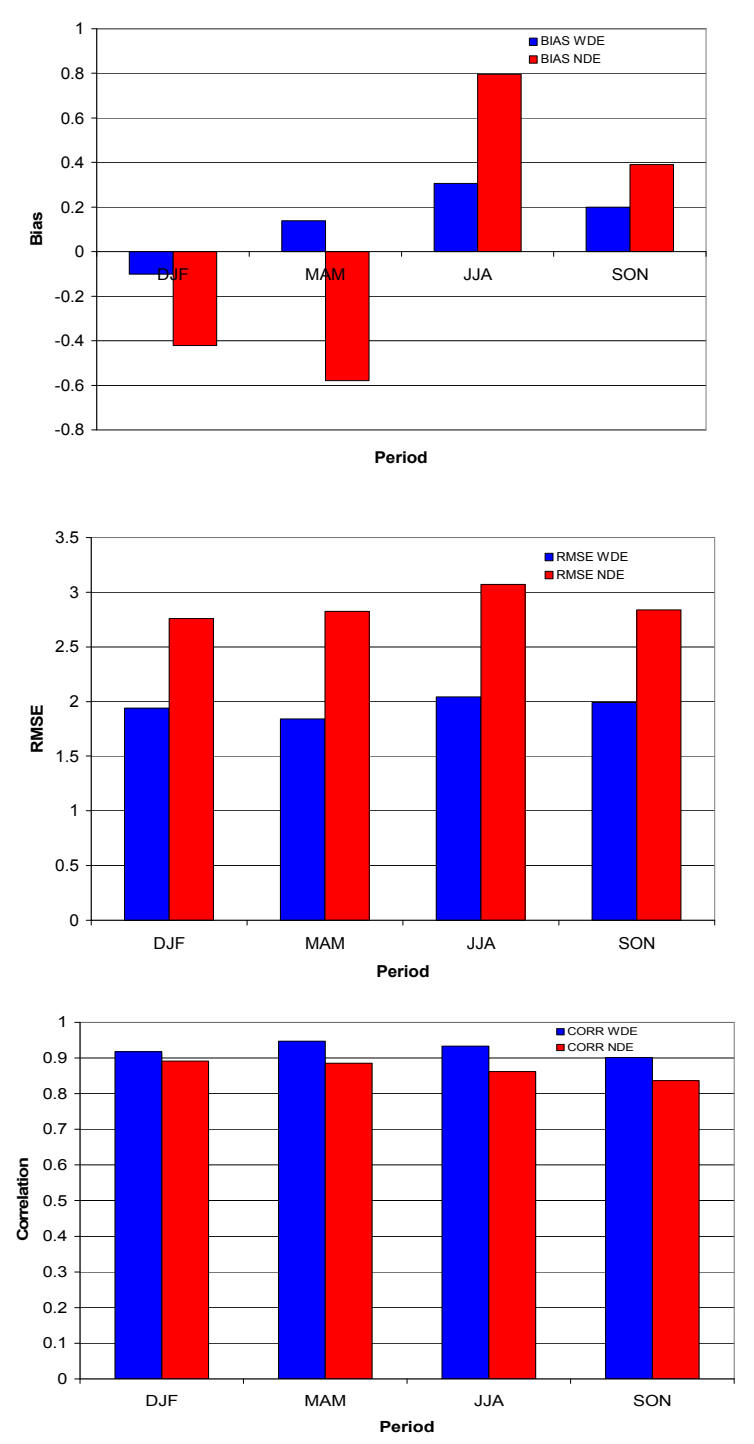

Fig. 6. Statistical parameters: bias (upper), RMSE (middle), correlation coefficient (lower) for the 6-year period of simulations (20022007) with dust effects (WDE) and without dust effects (NDE) for the surface temperature. 


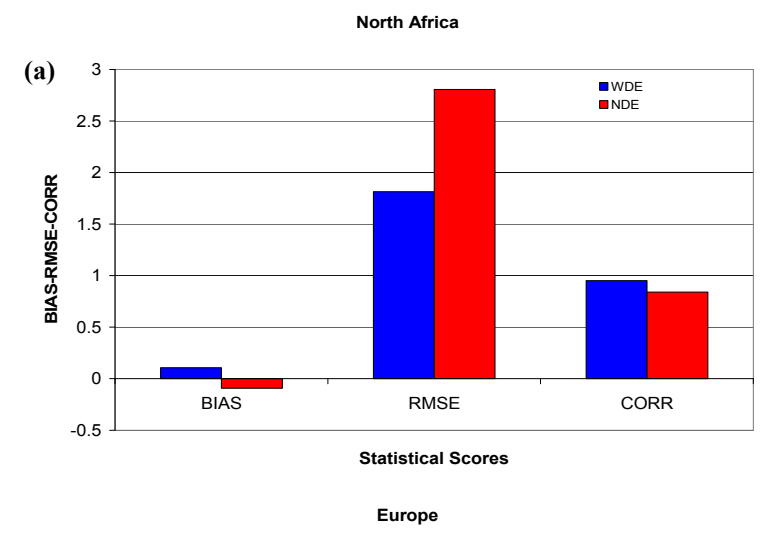

(b)

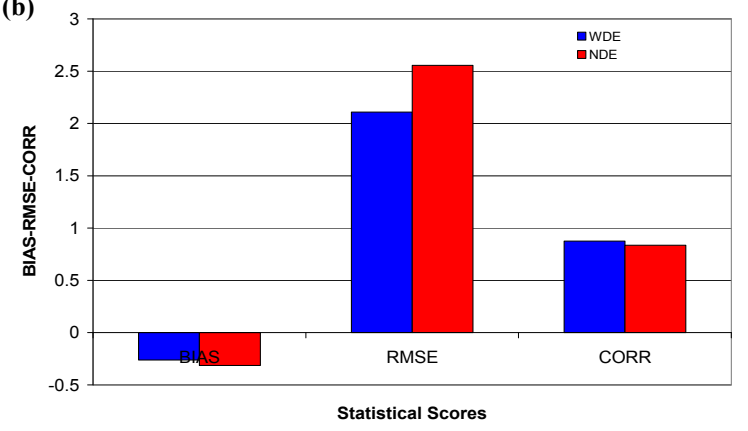

Fig. 7. Statistical parameters: Bias, RMSE and correlation coefficient for the spring period of the simulations (March-April-May) with dust effects (WDE) and without dust effects (NDE) for the surface temperature for North Africa (a) and Europe (b).

\section{Model sensitivity analysis - estimation of the impact on energy budget}

The life cycle of dust is defined as the emission, atmospheric loading and surface deposition of the desert dust particles. Quantification of the dust mass over the selected model domain is essential for the determination of the modified amounts in the energy budget due to the suspension of desert dust particles. To estimate the desert dust impact on the energy budget over the studied area, the 6-year model runs covering the period 2002-2007 were extensively analyzed. For this evaluation, the NDE model runs represent the radiation transfer parameters in clean (free of dust particles) atmospheric conditions, while the WDE simulations represent the dust transport events by taking into consideration the dust-radiation interaction processes.

Firstly, the areas that are mostly affected by the emission and transport of desert dust particles were detected. In Fig. 8a-d, the dust load (integrated column) values for the different seasons of the year are depicted across the studied area. Significant dust amounts appear to be over Chad with dust load values exceeding $1 \mathrm{~g} \mathrm{~m}^{-2}$, and at the northwestern part of the African continent over Mauritania and Algeria. The suspension of desert dust particles is also present across and around the Red Sea in the spring and summer periods. As reported by many studies (e.g. Moulin et al., 1997; Nickovic et al., 2001), the Saharan dust transport events are characterized by a strong seasonal variability. In particular, maximum dust impact is observed in central-eastern Mediterranean in spring, while the maximum is shifted in summer (and early autumn) to the central-western Mediterranean (Querol et al., 2009).

The seasonal differences in the incoming shortwave and longwave radiation fluxes reaching the surface are illustrated in Figs. 9 and 10. The differences in the shortwave fluxes appear to be negative during all periods of the year and greater during the warm spring and summer periods, approaching the value of $70 \mathrm{Wm}^{-2}$ over the extended desert areas of Chad (this value corresponds to an area of approximately $40000 \mathrm{~km}^{2}$ ), a very strong dust source. On the other hand, the depicted deviations over Europe and the Mediterranean are negligible during the cold periods because there is no significant dust transport. However, in spring, the discrepancies over European land areas is found to be as high as $10 \mathrm{Wm}^{-2}$ over the south and $5 \mathrm{Wm}^{-2}$ near the central European countries. Another region of increased differences in the incoming shortwave radiation that are at a maximum during summer is the northwestern African region and in particular over the southern desert areas of Morocco, where deviations greater than $40 \mathrm{Wm}^{-2}$ are modeled (Fig. 9c). As expected, the deviations between the two model setups (NDE and WDE) are more noticeable during the periods and in the areas with high dust productivity. In all cases, the suspension of dust aerosols leads considerable reduction of the incoming shortwave radiation due to scattering and absorption of the solar radiation. As illustrated in Fig. 10a, the total annual reduction of the incoming solar radiation (temporally integrated throughout the year) can be as high as $500 \mathrm{KWh} \mathrm{m}^{-2}$, which represents a significant portion of the total available solar radiation (by temporally integrating the hourly flux values - Fig. 10b). This reduction should be taken into consideration when modeling radiative fluxes for solar energy applications.

According to the model results, the incoming longwave radiation fluxes with the presence of dust particles are increased during all periods of the year (Fig. 11), with greater differences noticed in the spring. The longwave radiation emitted by the dust layer towards the surface during nighttime is superimposed with the daytime incoming shortwave and longwave radiation. As a result the incoming flux that reaches the surface is enhanced. This increase could approach $35 \mathrm{Wm}^{-2}$ over Chad and $25 \mathrm{Wm}^{-2}$ over southern Morocco during the warm seasons. This value over Morocco is quite similar to the values of $22 \mathrm{Wm}^{-2}$ (for spherical particles) and $24 \mathrm{Wm}^{-2}$ (for spheroid particles), as calculated by Otto et al. (2011) in a dust scenario based on in situ data measured in May 2006 in Morocco. Smaller differences are modeled over the Mediterranean Sea.

To better understand the annual variability of desert dust feedback at regional scales, the monthly average radiative forcing has been calculated over the entire model domain for 

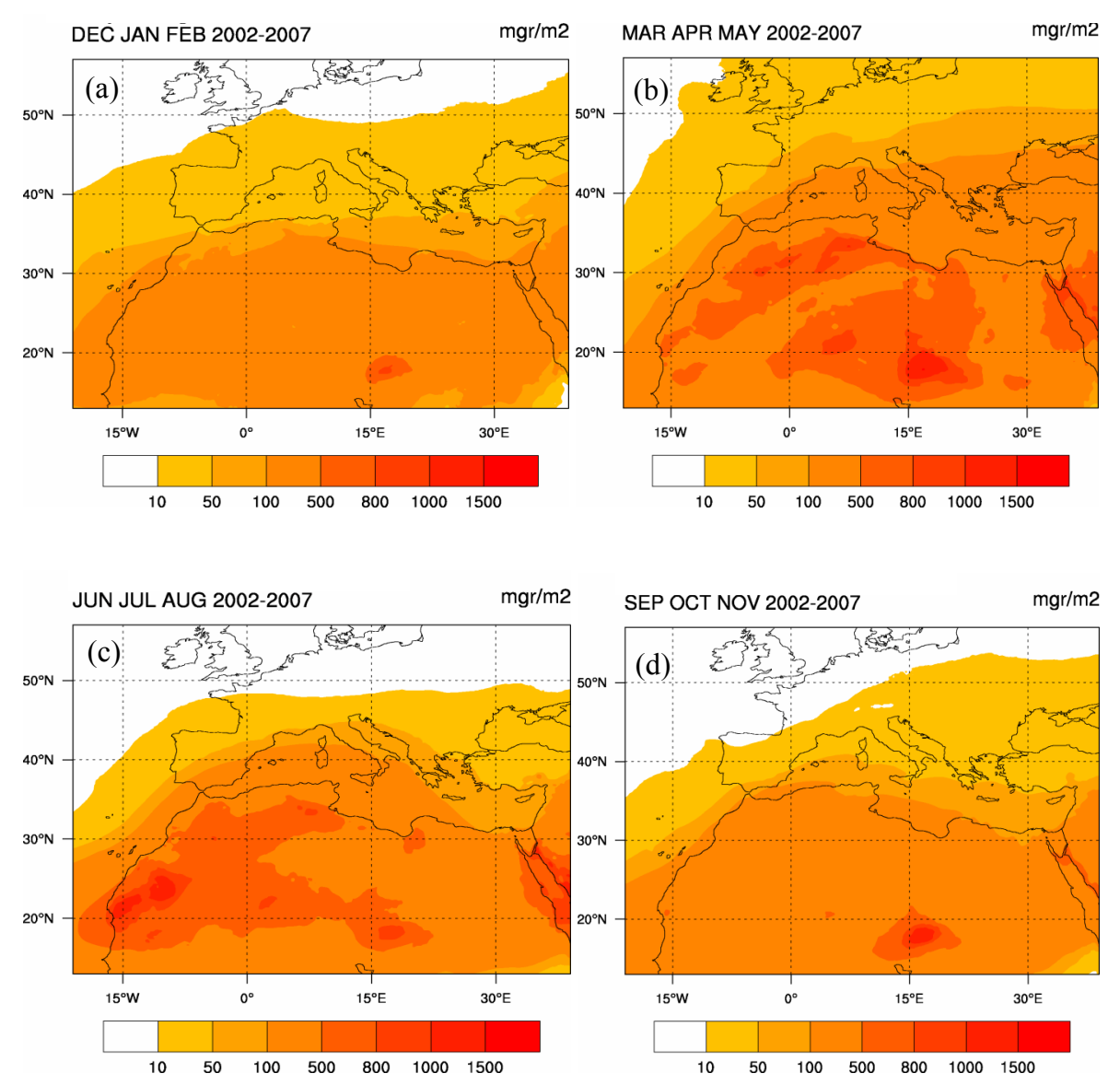

Fig. 8. Dust load as averaged during the 6-year period for the different seasons of the year, namely (a) winter, (b) spring, (c) summer and (d) autumn.

the incoming shortwave (Fig. 12a) and incoming longwave (Fig. 12b) radiation. As expected, the most profound effects are modeled during the spring, especially in May, reaching a maximum of approximately $-14 \mathrm{Wm}^{-2}$ for the shortwave, and $+6 \mathrm{Wm}^{-2}$ for the longwave.

The net atmospheric forcing by the mineral dust aerosols in the model simulations can be estimated as the difference in the radiative flux absorbed by the atmosphere between the two model configurations (WDE, NDE) over the model domain. This was derived for each season and the result is illustrated in Fig. 13a-d.

The radiative flux that is absorbed by the atmosphere can be determined through $F=\left(F_{\mathrm{TOA}} \downarrow-F_{\mathrm{TOA}} \uparrow\right)_{\mathrm{NDE}}-$ $\left(F_{\mathrm{TOA}} \downarrow-F_{\mathrm{TOA}} \uparrow\right)_{\mathrm{WDE}}=\mathrm{ABSORP} \mathrm{NDE}-\mathrm{ABSORP} \mathrm{WDE}_{\mathrm{W}}$

In the calculations we consider that the dust particles exert a negligible effect on the incoming radiation at the top of the atmosphere. In effect, negative values in Fig. 13a-d denote an increase in the atmospheric absorption due to dust feedback and positive values denote a decrease.

The modeled absorbed fluxes increase over the desert areas of the northern African region, while during the summer months differences can be also noticed over southern and central European areas. The energy amounts absorbed by the dust aerosols approach $10 \mathrm{Wm}^{-2}$ over land areas, while over the Red Sea the increase in the absorbed energy exceeds $20 \mathrm{Wm}^{-2}$ during the summer period. This can be attributed to the fact that the warm water of the Red Sea emits a large amount of longwave radiation that is trapped between the sea surface and the dust layer when there are increased concentrations of dust particles (greenhouse effect). On the contrary, the cold water of the North Atlantic emits less longwave radiation and the difference in atmospheric absorption detected is attributed to the emission from dust clouds (especially during the summer when dust particles move towards the Atlantic). The absorbed energy amounts by the dust particles can significantly influence the atmospheric stability by heating the lower tropospheric layer.

The analysis of the 3-D distributions of dust concentration reveals the vertical characteristics of the dust transport and suspension over the surface. Two vertical cross-sections of averaged dust concentration along the pathlines at $2 \mathrm{~W}$ for summer and $18 \mathrm{E}$ for spring are illustrated in Figs. 14a and $15 \mathrm{a}$, respectively. The greatest dust concentration values are obtained over the main dust sources and in particular at about 

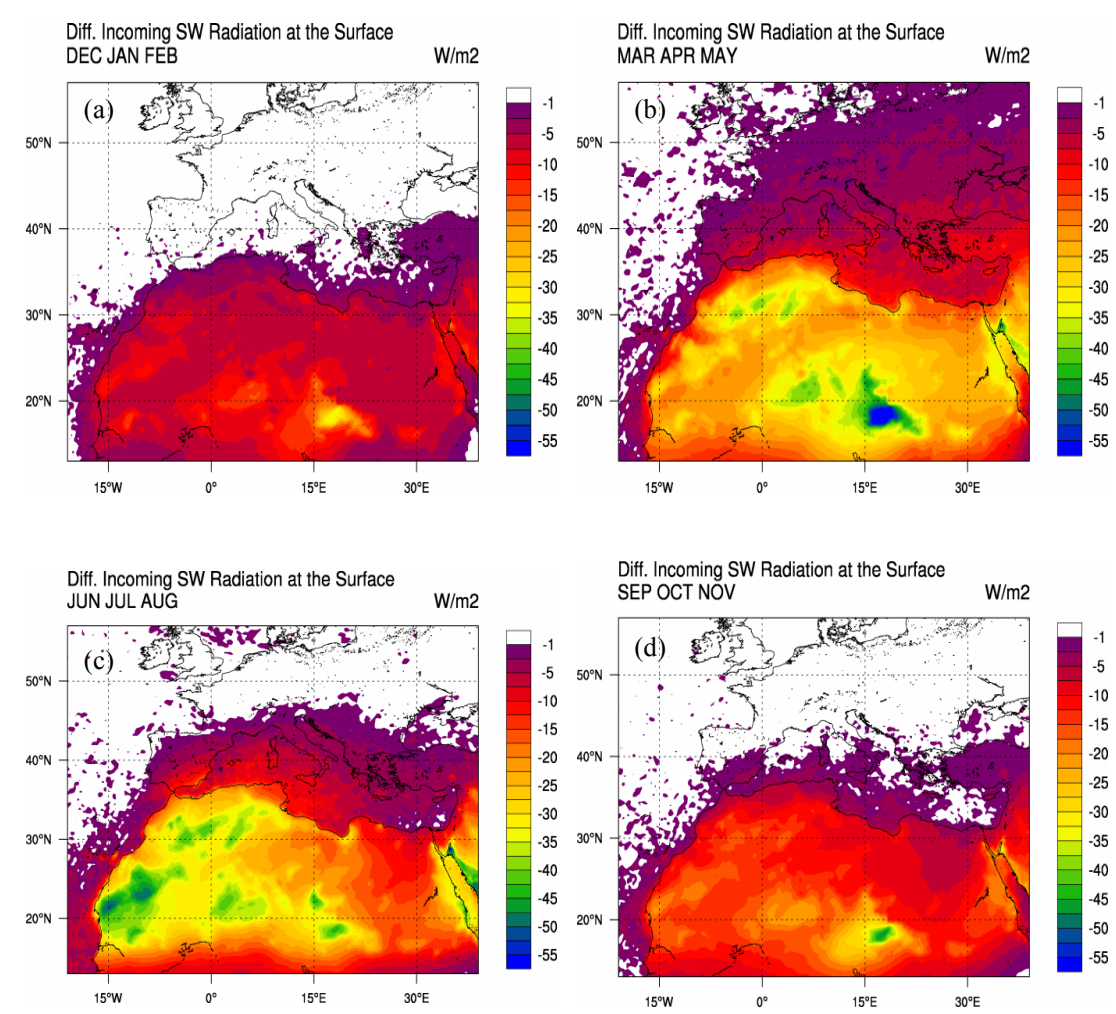

Fig. 9. Spatial difference between the model simulations (WDE - NDE) in the incoming shortwave radiation at the surface, as averaged during the winter (a), spring (b), summer (c) and autumn (d) seasons of the 6-year period.
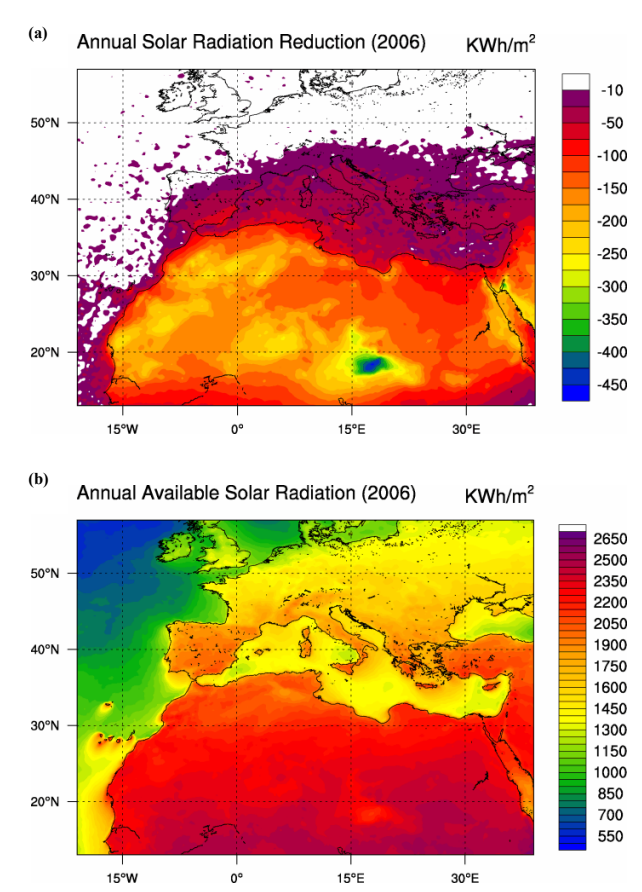

Fig. 10. Total reduction of the incoming solar radiation (integrated hourly throughout the year) for the year 2006 due to the scattering and absorption of desert dust particles (a) and the total available solar radiation for the same year (b).
20-25 N over the western part ( $2 \mathrm{~W})$ and over Chad in the central part $(18 \mathrm{E})$ of the north-African region. The area of increased dust concentrations close to the surface is more extended in the western part of the African continent (Fig. 14a), which is related to the existence of more wide-ranging dust source areas over this part. On the other hand, the high mountains in the central region of northern Africa (Fig. 15a) limit the extent of the dust source areas.

The vertical cross-sections of the temperature difference between the two model setups (WDE - NDE), as illustrated in Fig. 14b for the summer months and Fig. 15b for the spring months of the 6-year study period, reveal the importance of the dust radiative feedback: first of all dust particles reflect incoming radiation at high altitudes. This mechanism is reproduced by the model as an upper- to mid-tropospheric cooling of $\sim 0.1 \mathrm{~K}$ at $\sim 300 \mathrm{hPa}$. At the same time these particles increase the temperature of the dust layer through atmospheric absorption of the incoming SW radiation. According to the model results, this increase in the air temperature profile reaches $\sim 0.2 \mathrm{~K}$ at about $600 \mathrm{hPa}$ (mid-tropospheric heating).

Temperature decreases in the lower troposphere $(925 \mathrm{hPa}$ up to $825 \mathrm{hPa}$ ) up to $0.3 \mathrm{~K}$ are due to extinction of the incoming solar radiation, which is more profound in the western part of the African continent (Fig. 14b). An interesting feedback is that near source areas the modeled temperature of the atmospheric layer near the ground increases by $\sim 0.4 \mathrm{~K}$ 

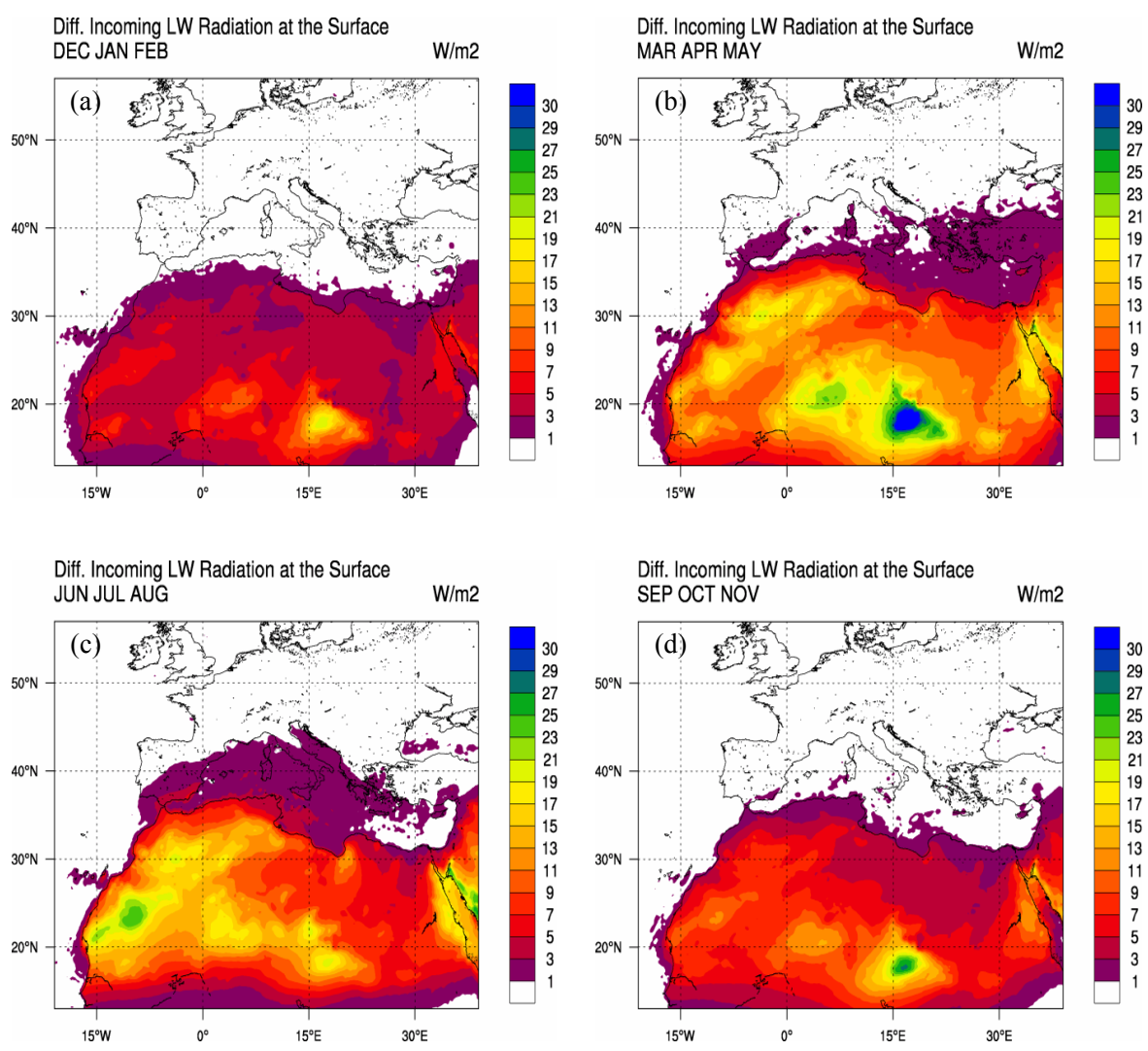

Fig. 11. Spatial difference between the model simulations (WDE - NDE) in the incoming longwave radiation at the surface, as averaged during the winter (a), spring (b), summer (c) and autumn (d) seasons of the 6-year period.
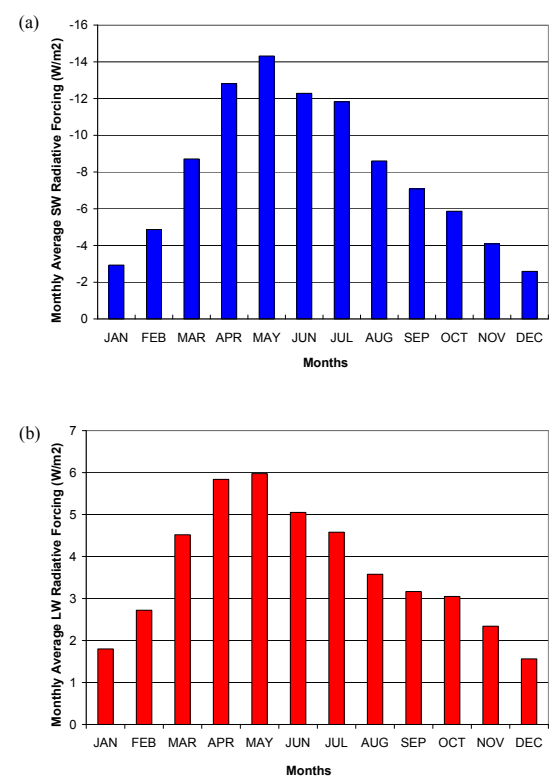

Fig. 12. Monthly average dust radiative forcing over the entire domain in (a) the incoming shortwave radiation and (b) the incoming longwave radiation on the surface. during the summer (Fig. 14b) and even up to $\sim 0.5 \mathrm{~K}$ during spring (Fig. 15b), even though the extinction of the incoming solar radiation is more profound there. This can be attributed to two superimposed factors: (1) during the day the dust particles absorb significant amounts of incoming solar radiation (as seen also in Fig. 11), raising the temperature of the near surface layer, and (2) during the night this dust layer "traps" longwave radiation emitted from the ground (greenhouse effect). As a result, the air temperature close to the surface increases, while a cooling of up to $-0.2 \mathrm{~K}$ is produced by the model inside the dust layer.

Far from the desert areas over the Mediterranean Sea, the surface temperature decreases due to scattering and absorption by the dust cloud. According to the model results, this reduction reaches $-0.2 \mathrm{~K}$ on average (Figs. $14 \mathrm{~b}, 15 \mathrm{~b}$ ).

\section{Conclusions}

This work represents a modeling study of the direct radiative effects of desert particles on the radiation budget of the atmosphere across the greater Mediterranean region. The DRE is investigated with the aid of the SKIRON/Dust modeling system. New radiative transfer mechanisms were incorporated in the atmospheric model and an extensive study was performed with the aid of radiation fluxes and temperature observational 

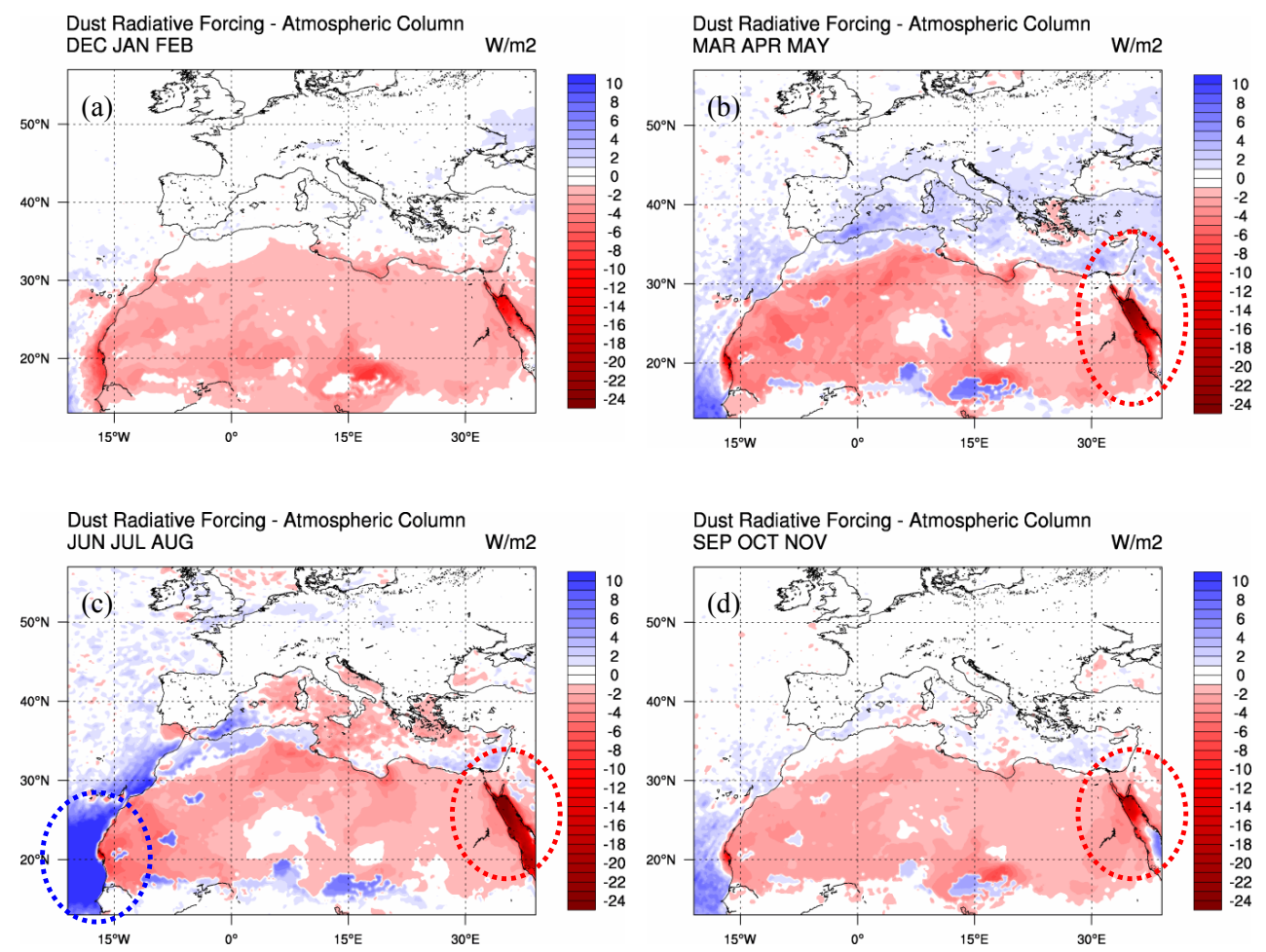

Fig. 13. Differences between the model simulations (WDE - NDE) in the atmospheric absorption at the top of the atmosphere, as averaged during the (a) winter, (b) spring, (c) summer and (d) autumn periods of the 6-year period.
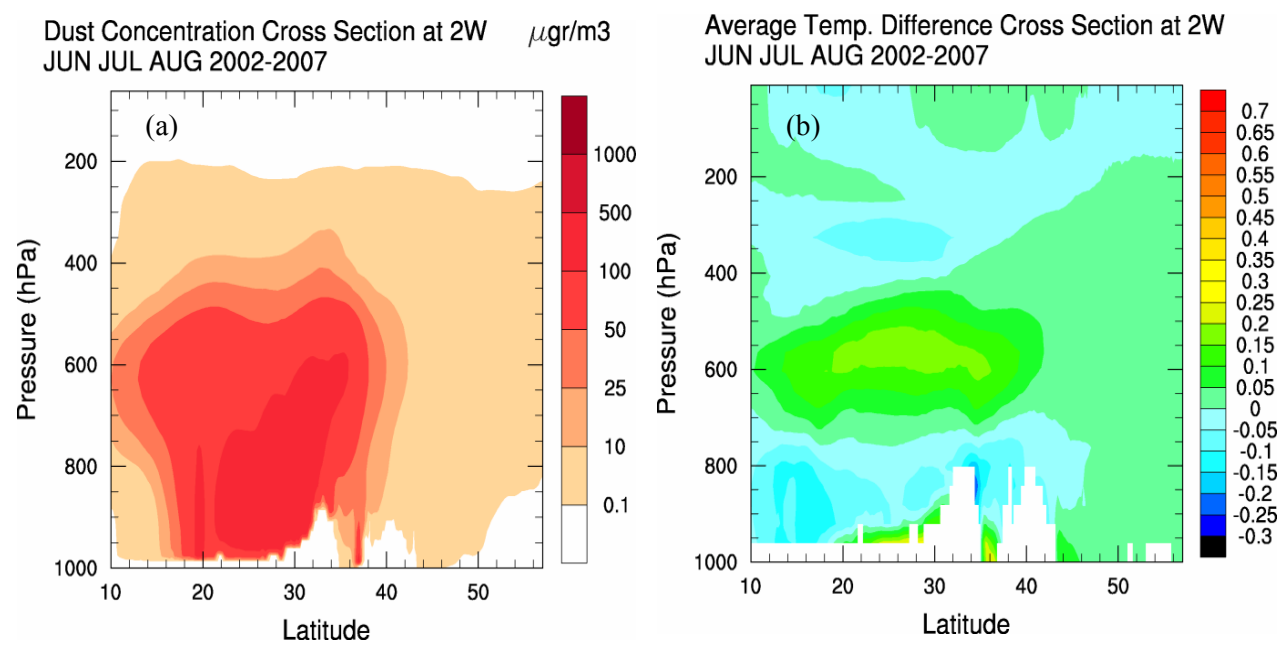

Fig. 14. Vertical cross-sections of (a) dust concentration at $2 \mathrm{~W}$ and of (b) temperature difference at $2 \mathrm{~W}$ (WDE - NDE), as averaged for the summer months of the 6-year period from the model simulations before and after incorporating dust-radiation interactions. The white color denotes the orography.

data. Using the updated system, the effects of desert dust particles on radiative transfer have revealed important findings, as summarized below.

The presence of dust particles in the atmosphere has a significant regional influence on the radiative transfer and energy distribution. Therefore, variations in dust particle pro- duction can have impacts on radiative properties and cloud formation. These interactions are not one-way; there are feedbacks that are critical for both regional-scale and climatological phenomena.

An extensive statistical evaluation with temperature data from more than 600 stations of the ECMWF operational 

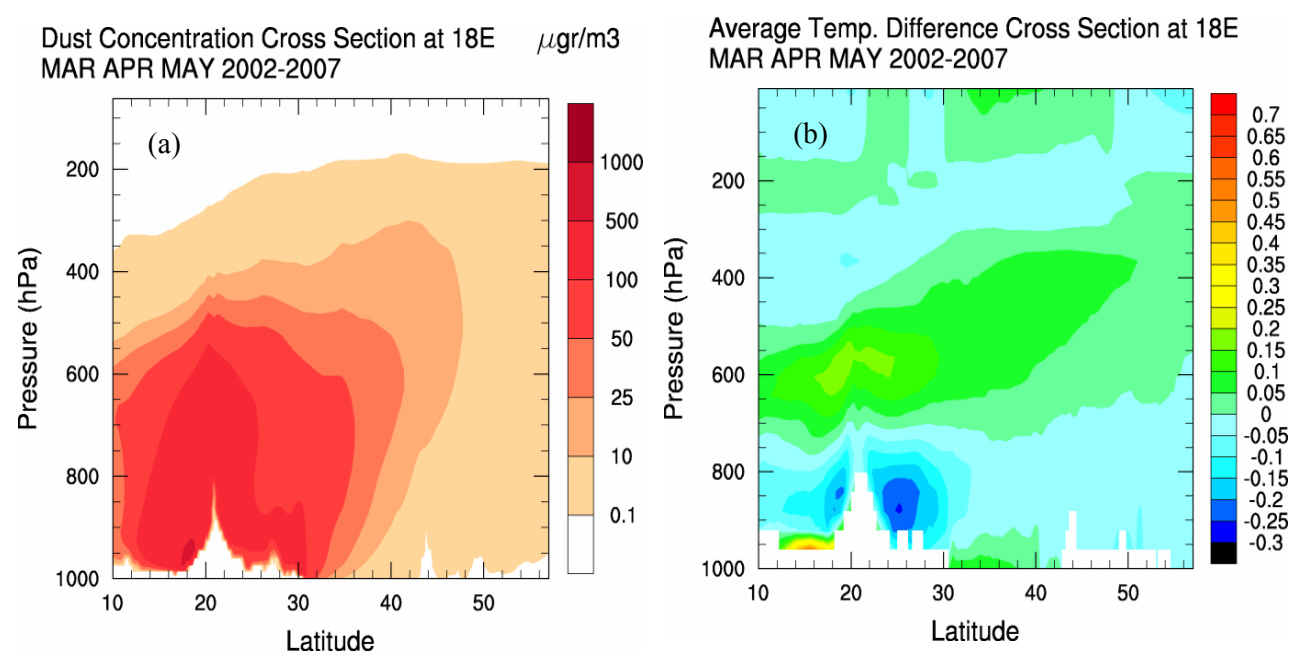

Fig. 15. Vertical cross-sections of (a) dust concentration at $18 \mathrm{E}$ and of (b) temperature difference at $18 \mathrm{E}$ (WDE - NDE), as averaged for the summer months of the 6-year period from the model simulations before and after incorporating dust-radiation interactions. The white color denotes the orography.

analysis has shown the improvement in the description of atmospheric processes when the dust-radiation feedback is included. This improvement is evident in all the statistical scores used and is most profound during the transitional seasons.

According to the model the suspension of desert dust particles decreases the amount of radiative energy reaching the surface. At the same time the atmospheric absorption is increased throughout the simulation domain, as the dust particles absorb both the incoming solar radiation and part of the longwave radiation emitted from the surface during the night.

In the vertical dimension, the phenomena are more complicated, as the redistribution of the energy has profound effects on the temperature profile: At high altitudes cooling is evident due to reflection from the dust clouds below. At the same time the temperature of the mid-tropospheric layers is increased due to absorption and the near-surface layer temperature drops due to extinction from above.

A notable attribute of dust is the greenhouse effect on areas with high particle concentrations. Even though the shading effect is dominant in these areas, the longwave trapping imposed by dust leads to an increase of the near surface temperature, rather than the expected reduction. This phenomenon is superimposed onto the emission of infrared radiation by the dust cloud itself, further intensifying the heating effect. The latter is an indication that the links and feedbacks between dust and climate are very complicated. It must also be noted that in this study the indirect effects of natural particles are not included and the total contribution of desert dust on a regional scale remains to be identified.

In general, the presence of desert dust particles in the atmosphere plays a key role in the energy distribution and the formation of the regional climate over the affected areas. The effects of airborne dust on the shortwave and longwave radiative fluxes at the surface should be carefully considered, including indirect effects, when model data is used to assess the available solar energy for power plant applications in desert areas. Finally, the dust influence on the energy parameters has a seasonal variability that is in line with the seasonality of the dust cycle events.

Acknowledgements. This work has been supported by the European Union 6th Framework Program CIRCE (Climate Change and Impact Research: The Mediterranean Environment) IP, contract number 036961, and by the European Union 7th Framework Program MARINA (MArine Renewable INtegrated Application Platform) Platform, Grant agreement number: 241402. We also thank the principle investigators and their staff for establishing and maintaining the AERONET sites used in this investigation.

Edited by: Y.-S. Chung

\section{References}

Albrecht, B.: Aerosols, cloud microphysics, and fractional cloudiness. Science, 245, 1227-1230, 1989.

Anderson, J. R, Hardy, E. E., Roach, J. T., and Witmer R. E.: A Land Use And Land Cover Classification System For Use With Remote Sensor Data, Geol. Surv. Prof. Paper, 964, 1-28, 1976.

Astitha, M., Kallos, G., Spyrou, C., O'Hirok, W., Lelieveld, J., and Denier van der Gon, H. A. C.: Modelling the chemically aged and mixed aerosols over the eastern central Atlantic Ocean - potential impacts, Atmos. Chem. Phys., 10, 5797-5822, doi:10.5194/acp-10-5797-2010, 2010.

Barker, H. W., Pincus, R., and Morcrette, J.-J.: The Monte-Carlo Independent Column Approximation: Application within largescale models. Proceedings of the GCSS/ARM Workshop on the 
Representation of Cloud Systems in Large-Scale Models, May 2002, Kananaskis, Alberta, Canada, 10 pp., 2003.

Betts, A. K. and Miller, M. J.: A new convective adjustment scheme, Part II: Single column tests using GATE wave, BOMEX, and arctic air-mass data sets, Quart. J. Roy. Meteor. Soc., 112, 693709, 1986.

Bohren, C. F. and Huffman, D. R.: Absorption and scattering of light by small particles. New York, Wiley-Interscience, 1983.

Clough, S. A., Shephard, M. W., Mlawer, E. J., Delamere, J. S., Iacono, M. J., Cady-Pereira, K., Boukabara, S., and Brown, P. D.: Atmospheric radiative transfer modelling: a summary of the AER codes, J. Quant. Spectrosc. Radiat. Transfer., 91, 233-244, 2005.

D'Almeida, G. A.: Desert aerosol characteristics and effects on climate. In: Leinen, M., and Sarnthein, M.: Palaeoclimatology and Palaeometeorology: Modern and Past Patterns of Global atmospheric transport, NATO ASI series, C, 282, 311-338, 1987.

di Sarra, A., Di Biagio, C., Meloni, D., Monteleone, F., Pace, G., Pugnaghi, S., and Sferlazzo, D.: Shortwave and longwave radiative effects of the intense Saharan dust event of 25-26 March 2010 at Lampedusa (Mediterranean Sea), J. Geophys. Res., 116, D23209, doi:10.1029/2011JD016238, 2011.

Dufrense, J. L., Gautier, C., and Ricchiazzi, P.: Longwave Scattering of Mineral Aerosols. Journal of Atmospheric Sciences, 59, 1959-1966, 2001.

Ek, M. and Mahrt, L.: OSU 1-D model, User Guide (version 1.0.4): A one-dimensional planetary boundary layer model with interactive soil layers and plant canopy, College of Oceanic and Atmospheric Sciences, Oregon state University, Corvallis, Oregon 97331-2209, 54 pp., 1991.

Haywood, J. M., Francis, P., Osborne, S., Glew, M., Loeb, N., Highwood, E., Tanre, D., Myhre, G., Paola Formenti, P., and Hirst, E.: Radiative properties and direct Radiative effect of Saharan dust measured by the C-130 aircraft during SHADE:1. Solar spectrum. J. Geophys. Res., 108, 8577, doi:10.1029/2002JD002687, 2003.

Heinold, B., Tegen, I., Schepanski, K., and Hellmuth, O.: Dust Radiative feedback on Saharan boundary layer dynamics and dust mobilization. Geophys. Res. Lett.,35, L20817, doi:10.1029/2008GL035319, 2008.

Helmert, J., Heinold, B., Tegen, I., Hellmuth, O., and Wendisch, M.: On the direct and semidirect effects of Saharan dust over Europe: A modelling study, J. Geophys. Res.,112, D13208, doi:10.1029/2006JD007444, 2007.

Henyey, L. C. and Greenstein, J. L.: Diffuse radiation in the galaxy, Astrophys. J., 93, 70-83, 1941.

Hess, M., Koepke, P., and Schult, I.: Optical Properties of Aerosols and Clouds: The Software Package OPAC, Bull. Am. Meteorol. Soc., 79, 831-844, 1998.

Iacono, M. J., Delamere, J. S., Mlawer, E. J., Shephard, M. W., Clough, S. A., and Collins, W. D.: Radiative forcing by long-lived greenhouse gases: Calculations with the AER Radiative transfer models, J. Geophys. Res., 113, D13103, doi:10.1029/2008JD009944, 2008.

Iacono, M. J., Delamere, J. S., Mlawer, E. J., and Clough, S. A.: Evaluation of upper tropospheric water vapor in the NCAR community climate model (CCM3) using modeled and observed HIRS radiances, J. Geophys. Res., 108, 4037, doi:10.1029/2002JD002539, 2003.
Intergovernmental Panel on Climate Change (IPCC): Changes in atmospheric constituents and radiative forcing: Climate change: the physical science basis, Cambridge University Press, New York, USA, and Cambridge, UK., 2007.

Janjic, Z. I.: The step-mountain eta coordinate model: Further developments of the convection, viscous sublayer, and turbulence closure schemes, Mon. Weather Rev., 122, 927-945, 1994.

Janjic, Z. I.: The step-mountain coordinate: physical package, Mon. Weather Rev., 118, 1429-1443, 1990.

Kain, J. S. and Fritsch, J. M.: A one-dimensional entraining/detraining plume model and its application in convective parameterization, J. Atmos. Sci., 47, 2784-2802, 1990.

Kalashnikova, O. V., Kahn, R., Sokolik, I. N. and Wen-Hao, Li: Ability of multiangle remote sensing observations to identify and distinguish mineral dust types: Optical models and retrievals of optically thick plumes, J. Geophys. Res., 110, D18S14, doi:10.1029/2004JD004550, 2005.

Kallo,s G., Spyrou, C., and Mitsakou, C.: Short and Long Wave Radiative Forcing from Desert Dust and Impacts on Weather and Climate, European Geosciences Union General Assembly 2009, EGU2009-8867, Vienna, Austria, 19-24 April 2009.

Kallos, G., Papadopoulos, A., Katsafados, P., and Nickovic, S.: Transatlantic Saharan dust transport: Model simulation and results. Journal Of Geophysical Research,111, D09204, doi:10.1029/2005JD006207, 2006/

Kallos, G., Nickovic, S., Papadopoulos, A., Jovic, D., Kakaliagou, O., Misirlis, N., Boukas, L., Mimikou, N., Sakellaridis, G., Papageorgiou, J., Anadranistakis, E., and Manousakis, M.: The regional weather forecasting system Skiron: An overview. Proceedings of the Symposium on Regional Weather Prediction on Parallel Computer Environments, 15-17 October 1997, Athens, Greece, 109-122, 1997a.

Kallos, G., Nickovic, S., Jovic, D., Kakaliagou, O., Papadopoulos, A., Misirlis, N., Boukas, L., and Mimikou, N.: The ETA model operational forecasting system and its parallel implementation. Proceedings of the 1st Workshop on Large-Scale Scientific Computations, 7-11 June 1997, Varna, Bulgaria, 15 pp., 1997 b.

Kaufman, Y. J., Tanre, D., Holben, B. N., Mattoo, S., Remer, L. A., Eck, T. F., Vaughan, J., and Chatenet, B.: Aerosol radiative impact on spectral solar flux at the surface, derived from principalplane sky measurements, J. Atmos. Sci., 59: 635-646, 2002.

Kahn, R. A., Yu, H., Schwartz, S. E., Chin, M., Feingold, G., Remer, L. A., Rind, D., Halthore, R., and DeCola, P.: Introduction, Atmospheric Aerosol Properties and Climate Impacts A Report by the U.S. Climate Change Science Program and the Subcommittee on Global Change Research, edited by: Chin, M., Kahn, R. A., and Schwartz, S. E., National Aeronautics and Space Administration, Washington, D.C., USA, 2009.

Levin, Z., Teller, A., Ganor, E., and Yin, Y.: On the interactions of mineral dust, sea-salt particles and clouds: A measurement and modelling study from the Mediterranean Israeli Dust Experiment campaign, J. Geophys. Res., 110, D20202, doi:10.1029/2005JD005810, 2005.

Liao, H., Seinfeld, J. H., Adams, P. J., and Mickley, L. J.: Global radiative forcing of coupled tropospheric ozone and aerosols in a unifi edgeneral circulation model, J. Geophys. Res., 109, D16207, doi:10.1029/2003JD004456, 2004.

Liou, K. N. and Ou, S.-C.: The Role of Cloud Microphysical Processes in Climate: An Assessment From a One-Dimensional Per- 
spective, J. Geophys. Res., 94, 8599-8607, 1989.

Marticorena, B. and Bergametti, G., Modelling the atmospheric dust cycle: 1 . Design of a soil-derived dust emission scheme, J. Geophys. Res., 100, 16415-16430, 1995.

Meloni, D., di Sarra, A., Di Iorio, T., and Fiocco, G.: Direct radiative forcing of Saharan dust in the Mediterranean from measurements at Lampedusa Island and MISR spaceborne observations, J. Geophys. Res.,109, D08206, 15 pp., doi:10.1029/2003JD003960, 2004.

Mesinger, F.: A blocking technique for representation of mountains in atmospheric models, Riv. Meteor. Aeronaut., 44, 195-202, 1984.

Mesinger, F., Chou, C.C., Gomes, L., Jovic, D., Bastos, P., Bustamante, J. F., Lazic, L., Lyra, A. A., Morelli, S., Ristic, I., and Veljovic, K.: An upgraded version of the Eta model. Meteorol. Atmos. Phys., 116, 63-79, doi:10.1007/s00703-012-0182-z, 2012.

Mesinger, F., Janjic, Z. I., Nickovic, S., Gavrilov, D., and Deaven, D. G.: The step-mountain coordinate: model description and performance for cases of Alpine lee cyclogenesis and for a case of an Appalachian redevelopment, Mon. Weather Rev., 116, 14931518, 1988.

Miller, D. A and White, R. A.: A Conterminous United States Multilayer Soil Characteristics Dataset for Regional Climate and Hydrology Modelling, Earth Interactions, 2, Paper No. 2, 1998.

Mishchenko, M. I., Travis, L. D., and Lacis, A. A.: Scattering, Absorption, and Emission of Light by Small Particles, Cambridge University Press, Cambridge, 2002.

Mlawer, E. J., Taubman, S. J., Brown, P. D., Iacono, M. J., and Clough, S. A.: RRTM, a validated correlated-k model for the longwave, J. Geophys. Res., 102, 16663-16682, 1997.

Morcrette, J.-J.: Impact of the radiation-transfer scheme RRTM in the ECMWF forecasting system, ECMWF Newsletter No. 91, 2001.

Moulin C., Lambert, C. E., Dulac, F., and Dayan, U.: Control of atmospheric export of dust by the North Atlantic Oscillation, Nature, 387, 691-4, 1997.

Müller, D., Lee, K.-H., Gasteiger, J., Tesche, M., Weinzierl, B., Kandler, K., Müller, T., Toledano, C., Otto, S., Althausen, D., Ansmann, A.: Comparison of optical and microphysical properties of pure Saharan mineral dust observed with AERONET Sun photometer, Raman lidar, and in situ instruments during SAMUM 2006, J. Geophys. Res., 117, D707211, doi:10.1029/2011JD016825, 2012.

Nakajima, T., Tanaka, M., Yamano, M., Shiobara, M., Arao, K., and Nakanishi, Y.: Aerosol optical characteristics in the yellow sand events observed in May 1982 at Nagasaki, Part 2. Model, J. Meteorol. Soc. Jpn., 67, 279-291, 1989.

Nickovic, S., Kallos, G., Papadopoulos, A., and Kakaliagou, O.: A model for prediction of desert dust cycle in the atmosphere, J. Geophys. Res., 106, 18113-18129, 2001.

Oreopoulos, L. and Barker, H. W.: Accounting for subgrid-scale cloud variability in a multi-layer 1-D solar radiative transfer algorithm, Quart. J. Roy. Meteor. Soc.., 125, 301-330, 1999.

Otto, S., Trautmann, T., and Wendisch, M.: On realistic size equivalence and shape of spheroidal Saharan mineral dust particles applied in solar and thermal radiative transfer calculations, Atmos. Chem. Phys., 11, 4469-4490, doi:10.5194/acp-11-44692011, 2011.
Pace, G., di Sarra, A., Meloni, D., Piacentino, S., and Chamard, P.: Aerosol optical properties at Lampedusa (Central Mediterranean) 1 . Influence of transport and identification of different aerosol types, Atmos. Chem. Phys., 6, 697-713, 2006, http://www.atmos-chem-phys.net/6/697/2006/.

Pandis, S. N., Wexler, A. S., and Seinfeld, J. H.: Secondary organic aerosol formation and transport, II, Predicting the ambient secondary organic aerosol size distribution, Atmos. Environ., 27A, 2403-2416, 1993.

Pandithurai G., Dipu, S., Dani, K. K., Tiwari, S., Bisht, D. S., Devara, P. C. S., and Pinker, R. T.: Aerosol radiative forcing during dust events over New Delhi, India. J. Of Geophys. Res., 113, D13209, doi:10.1029/2008jd009804, 2008.

Papadopoulos, A., Katsafados, P., Kallos, G., and Nickovic, S.: The Poseidon weather forecasting system - An overview, The Global Atmosphere and Ocean Systems, 8, 219-237, 2002.

Perez C., Nickovic, S., Baldasano, J. M., Sicard, M., Rocadenbosch, F., and Cachorro, V. E.: A long Saharan dust event over the western Mediterranean: Lidar, Sun photometer observations, and regional dust modelling, J. Geophys. Res., 111, D15214, doi:10.1029/2005JD006579, 2006.

Pincus, R., Barker, H. W., and Morcrette, J.-J.: A fast, flexible, approximate technique for computing radiative transfer in inhomogeneous clouds. J. Geophys. Res., 108, 4376, D13, doi:10.1029/2002JD003322, 2003.

Rothman, L. S., Gordon, I. E., Barbe, A., Chris Benner, D., Bernath, P. F., Birke, M., Boudon, V., Brown, L. R., Campargue, A., Champion, J.-P., Chance, K., Coudert, L. H., Dana, V., Devi, V. M., Fally, S., Flaud, J.-M., Gamache, R. R, Goldmanm, A., Jacquemart, D., Kleiner, I., Lacome, N., Lafferty, W.J., Mandin, J.-Y., Massie, S. T., Mikhailenko, S.N., Miller, C.E., Moazzen-Ahmadi, N., Naumenko, O. V., Nikitin, A. V., Orphal, J., Perevalov, V. I., Perrin, A., Predoi-Cross, A., Rinsland, C. P., Rotger, M., Simeckova, M., Smith, M. A. H., Sung, K., Tashkun, S. A., Tennyson, J., Toth, R. A., Vandaele, A. C., and Vander Auwer, J.: The HITRAN 2008 molecular spectroscopic database, Journal of Quantitative Spectroscopy \& Radiative Transfer, 110, 533-572, 2009.

Quenzel, H. and Müller, H.: Optical properties of single Mie particles: Diagrams of intensity, extinction, scattering and absorption efficiencies. Universität München, Meteorologisches Institut, Wiss. Mit. Nr. 34, 59 pp. (Available from Meteorologisches Institut, Theresienstraße 37, D-80333 München, Germany), 1978.

Querol X., Alastuey, A., Pey, J., Cusack, M., Perez, N., Mihalopoulos, N., Theodosi, C., Gerasopoulos, E., Kubilay, N. and Kocak, M.: Variability in regional background aerosols within the Mediterranean, Atmos. Chem. Phys., 9, 4575-4591, 2009, http://www.atmos-chem-phys.net/9/4575/2009/.

Reddy, M. S., Boucher, O., Balanski, Y., and Schulz, M.: Aerosol optical depths and direct radiative perturbations by species and source type. Geophys. Res. Lett., 32, L12803, doi:10.1029/2004GL021743, 2005.

Schulz, M., Balkanski, Y. J., Guelle, W., and Dulac, F.: Role of aerosol size distribution and source location in a threedimensional simulation of a Saharan dust episode tested against satellite-derived optical thickness, J. Geophys. Res., 103, 1057910592, 1998. 
Slingo, A., Ackerman, T. P., Allan, R. P., Kassianov, E. I., McFarlane, S. A., Robinson, G. J., Barnard, J. C., Miller, M. A., Harries, J. E., Russell, J. E., and Dewitte, S.: Observations of the impact of a major Saharan dust storm on the atmospheric radiation balance, Geophys. Res. Lett., 33, L24817, doi:10.1029/2006GL027869, 2006.

Sokolik, I. N., Winker, D. M., Bergametti, G., Gillette, D. A., Carmichael, G., Kaufman, Y., Gomes, L., Schuetz, L., and Penner, J. E.: Introduction to special section: Outstanding problems in quantifying the radiative impacts of mineral dust, J. Geophys. Res., 106, 18015-18028, 2001.

Sokolik, I. N. and Toon, O. B.: Direct radiative forcing by anthropogenic airborne mineral aerosols, Nature, 381, 681-683, 1996.

Solomos, S., Kallos, G., Kushta, J., Astitha, M., Tremback, C., Nenes, A., and Levin, Z.: An integrated modeling study on the effects of mineral dust and sea salt particles on clouds and precipitation, Atmos. Chem. Phys., 11, 873-892, doi:10.5194/acp11-873-2011, 2011.

Spyrou, C., Mitsakou, C., Kallos, G., Louka, P., and Vlastou, G.: An improved limited area model for describing the dust cycle in the atmosphere, J. Geophys. Res., 115, D17211, doi:10.1029/2009JD013682, 2010.

Stokowski, D.: The addition of the direct radiative effect of atmospheric aerosols into the Regional Atmospheric Modelling System (RAMS), DoD Center for Geosciences/Atmospheric Research under grant DAAD 19-02-2-2005, Paper No 764, Department of Atmospheric Science, Colorado State University, 2005.

Tegen, I.: Modelling the mineral dust aerosol cycle in the climate system, Quat. Sci. Rev., 22, 1821-1834, 2003.
Tegen, I. and Lacis, A. A.: Modelling of particle size distribution and its influence on the radiative properties of mineral dust aerosol, J. Geophys. Res., 101, 19237-19244, 1996.

Turner, D. D., Tobin, D. C., Clough, S. A., Brown, P. D, Ellingson, R. G., Mlawer, E. J., Knuteson, R. O., Revercomb, H. E., Shippert, T. R., Smith, W. L., and Shephard, M. W.: The QME AERI LBLRTM: A closure experiment for downwelling high spectral resolution infrared radiance, J. Atmos. Sci., 61, 26572675, 2004.

Twomey, S.: The influuence of pollution on the shortwave albedo of clouds, J. Atmos. Sci., 34, 1149-1152, 1977.

Wang, Y., Zhuanga, G., Sund, Y., Anb, Z.: Water-soluble part of the aerosol in the dust storm season-evidence of the mixing between mineral and pollution aerosols, Atmos. Environ., 39, 7020-7029, 2005.

Wilks, D. S.: Statistical Methods in the Atmospheric Sciences, Academic Press NY, 33-277, 1995.

Wiscombe, W. J.: Improved Mie scattering algorithms, Applied Optics, 19, 1505-1509, 1980.

Yoshioka, M., Mahowald, N. M., Conley, A. J., Collins, W. D., Fillmore, D. W., Zender, C. S., and Coleman, D. B.: Impact of Desert Dust Radiative Forcing on Sahel Precipitation: Relative Importance of Dust Compared to Sea Surface Temperature Variations, Vegetation Changes, and Greenhouse Gas Warming, American Meteorological Society, 20, 1445-1467, doi:10.1175/JCLI4056.1, 2007. 